\title{
A systematic review of patients' perspectives on the subcutaneous route
} of medication administration

Ridyard, Colin; Dawoud, D.M.; Tuersley, L.V.; Hughes, D.

\section{Patient: Patient-Centered Outcomes Research}

\author{
DOI: \\ $10.1007 / \mathrm{s} 40271-015-0160-\mathrm{x}$
}

Published: 01/08/2016

Peer reviewed version

Cyswllt i'r cyhoeddiad / Link to publication

Dyfyniad o'r fersiwn a gyhoeddwyd / Citation for published version (APA):

Ridyard, C., Dawoud, D. M., Tuersley, L. V., \& Hughes, D. (2016). A systematic review of patients' perspectives on the subcutaneous route of medication administration. Patient: Patient-Centered Outcomes Research, 9(4), 281-292. https://doi.org/10.1007/s40271-015-0160$\mathrm{X}$

\footnotetext{
Hawliau Cyffredinol / General rights

Copyright and moral rights for the publications made accessible in the public portal are retained by the authors and/or other copyright owners and it is a condition of accessing publications that users recognise and abide by the legal requirements associated with these rights.

- Users may download and print one copy of any publication from the public portal for the purpose of private study or research.

- You may not further distribute the material or use it for any profit-making activity or commercial gain

- You may freely distribute the URL identifying the publication in the public portal?

Take down policy

The final publication is available at Springer via http://link.springer.com/article/10.1007/s40271-015-0160-x

Take down policy

If you believe that this document breaches copyright please contact us providing details, and we will remove access to the work immediately and investigate your claim.
} 
1 Title: A systematic review of patients' perspectives on the subcutaneous route of medication

2 administration.

3

4 Authors: Colin H Ridyard ${ }^{1}$ PhD, Dalia M M Dawoud ${ }^{2}$ PhD, Lorna V Tuersley ${ }^{1}$ PhD

MRPharmS and Dyfrig A Hughes ${ }^{1}$ PhD, MRPharmS

6

$7 \quad{ }^{1}$ Centre for Health Economics and Medicines Evaluation, Bangor University

$8 \quad{ }^{2}$ Clinical Pharmacy Department, Faculty of Pharmacy, Cairo University

9

Corresponding Author: Professor Dyfrig A. Hughes, Centre for Health Economics and

Medicines Evaluation, Bangor University, Ardudwy, Normal Site, Holyhead Road, Bangor

Tel: +44 (0)1248382950

E-mail: d.a.hughes@bangor.ac.uk

Keywords: Subcutaneous drug administration, administration, subcutaneous injections, injection devices, systematic review, patient preference, patient satisfaction

Running Head: Review of patient perspectives on subcutaneous medications

Acknowledgements: This research is supported the MRC North West Hub in Trial Methodological Research: G0800792

Conflict of Interest: CR, DD, LT, DH declare no conflict of interest. All authors have completed the Unified Competing Interest form at www.icmje.org/coi_disclosure.pdf

27 (available on request from the corresponding author) and declare: no support from any 
organisation for the submitted work; no financial relationships with any organisations that might have an interest in the submitted work in the previous 3 years; no other relationships or activities that could appear to have influenced the submitted work.

32 Contributions: CHR and DAH contributed substantially to the conception and design of the 33 work. All authors made contributions to the acquisition, analysis, or interpretation of data.

34 CHR and LT drafted and DAH redrafted the paper; all authors revised it critically for important intellectual content, and gave their final approval of the version to be published. All authors agree to be accountable for all aspects of the work in ensuring that questions related

37 to the accuracy or integrity of any part of the work are appropriately investigated and resolved. 


\section{$41 \quad$ Key points for decision makers}

42 - Subcutaneous drug administration is used increasingly in place of intravenous drug

43 delivery and is an alternative to oral dosing for some treatments

44 - Studies of patients' perspectives typically assess ease of use, patient satisfaction and

45 fear of adverse reactions relating to treatment administration

- Among the studies assessed, oral, subcutaneous infusion, intramuscular injection, and needle-free injection devices were not favoured over subcutaneous injections

48

49 
Background: Subcutaneous injections allow for self-administration, but consideration of patients' perspectives on treatment choice is important to ensure adherence. Previous systematic reviews have been limited in their scope for assessing preferences in relation to other routes of administration

Aim: To examine patients' perspectives on subcutaneously administered, self-injectable medications when compared with other routes or methods of administration for the same medicines.

60

Methods: Nine electronic databases were searched for publications since 2000 using terms pertaining to methods of administration, choice behaviour and adverse effects. Eligibility for inclusion was determined through reference to specific criteria by two independent reviewers. Results were described narratively.

Results: Of the 1,726 papers screened, 85 met the inclusion criteria. Studies were focused mainly on methods of insulin administration for diabetes but also included treatments for paediatric growth disorders, multiple sclerosis, HIV and migraine. Pen devices and autoinjectors were favoured over administration with needle and syringe; particularly with respect to ergonomics, convenience and portability. Inhalation appeared to be more acceptable than subcutaneous injection (in the case of insulin), but it is less certain how subcutaneous infusion, intramuscular injection, and needle-free injection devices compare with subcutaneous injections in terms of patient preference.

Conclusions: The review identified a number of studies showing the importance of the methods and routes of drug delivery on patient choice. However, studies were prone to bias 
77 and further robust evidence, based on methodologically sound approaches, is required to 78 demonstrate how patient choice might translate to improved adherence. 


\section{Introduction}

Patients' attitudes towards their medicines are influenced by many factors, including their perceived (or real) benefits and harms, previous experience of use, perceptions of their illness, satisfaction with treatment and personal preferences [1]. Thus achieving optimal treatment outcomes requires that the right patients get the right choice of medicine at the right time [2]. This notion of "medicines optimisation" also encompasses encouraging patients to take their medicines correctly, avoid taking unnecessary medicines, reduce wastage of medicines, and improve medicines safety [2,3]. For some medicines, offering patients different methods or routes of drug administration may help achieve a patientcentred approach to care thereby improving medication adherence, especially in the context of parenteral administration [4-6].

While oral dosing is the posology of choice for chronic disease management, this may not be possible for some medicines (e.g. because of low bioavailability) or desirable for others (e.g. because of poor targeting of the site of action). The subcutaneous (SC) route of administration is being used increasingly, particularly as alternative formulations of biologics are developed for conditions such as cancers and inflammatory diseases [7]. Treatments including trastuzumab and rituximab -previously only available for intravenous administration- are now licensed for SC use. Compared with other routes of parenteral administration, subcutaneously-injectable formulations may offer advantages in terms of convenience, ease of use and the possibility of self-administration, which can also save health professionals' time and, thus, reduce costs. However, barriers to the use of SC injections, such as anxiety [8] and adverse, injection-site reactions [9] may have a negative impact on adherence and the benefits of such treatments. 
105 There also exists several methods of SC administration, and patients' satisfaction with, or

106 preferences towards delivery devices are likely to differ. In the case of insulin, for instance,

107 patients consider pen devices to be a more acceptable method of administration than

108 conventional vial and syringe or pre-filled syringes [10]. These offer improved portability,

109 convenience and ease of use and reduced injection-site pain leading to better patient

110 satisfaction. Compared to vials and syringes, use of insulin pen devices may consequently

111 improve adherence and reduce healthcare resource use and associated costs [11].

113 Whilst differences in the pharmacokinetics and efficacy of competing methods and routes of

114 drug administration are well documented, less is known of patients' perspectives. Relevant

115 research methods include the use of self-reported outcomes, such as from rating and

116 ranking scales, willingness-to-pay studies, discrete choice experiments, conjoint analyses

117 and best-worst scaling exercise.

119 This review aims to examine patients' perspectives on subcutaneously administered, self-

120 injectable medications. It focuses on study methodologies and on examining how patients'

121 choices compare for different devices and routes of administration.

122 
The systematic review protocol was registered with the All Wales Systematic Reviews Register [12,13], conducted according to the methods of the Centre for Reviews and Dissemination [14] and reported according to the Preferred Reporting Items for Systematic Reviews and Meta-Analyses (PRISMA) statement [15].

Sources searched: The following databases were searched during July 2013 , using a combination of MeSH and free text searches: Embase (Ovid), CINAHL (EBSCO Host), Pubmed, Cochrane (including the Cochrane Database of Systematic Reviews), TOXLINE (ProQuest), PsycARTICLES (ProQuest), PsycINFO (ProQuest), Health \& Safety Science Abstracts (ProQuest), Physical Education Index (ProQuest).

Search terms: Free-text or MeSH heading terms pertaining to (i) the route of administration were combined using the Boolean operator AND with terms relevant for (ii) identifying choice behaviour and methods of elicitation, and (iii) (perceived) adverse injection-site reactions or process utility:

(i) subcutaneous drug administration OR subcutaneous injections OR subcutaneous injection OR subcutaneous drug administration OR injection devices OR self injection (ii) Prefer* OR "trade-off" OR "patient participation" OR "patient satisfaction" OR "decision making" OR elicit* OR assess* OR "choice behaviour" OR "choice behavior" OR (Conjoint OR choice* AND (analys* OR experiment* OR elicit* OR assess* OR measurement) (iii) injection site pain OR injection pain OR adverse drug reaction OR injection site reaction OR cutaneous reaction OR "process utility" OR (("treatment related attributes" OR "drug administration" OR "dose frequency") AND (utilities OR "utility measurement")) 
device, including hypothetical scenarios; in patients currently or likely to become responsible

149 for self-administration of SC medication; and which measured patients' perspectives towards

150 to the health technology, adverse effects attributable to the method / route of administration

151 such as pain or injection site reactions, or satisfaction.

152 Exclusion criteria: Studies were excluded if they: were published prior to 2000; written in a

153 language other than English; were reviews, case studies, decision models, news, correspondence, commentaries; were published as conference abstracts or posters or in books, trade journals; were animal, mechanistic or pharmacokinetic studies; assessed vaccines, anaesthesia or palliative care; or considered injection drug users or nonambulatory patients.

Review methods: Titles and abstracts were read and eligibility assessment was performed independently by two reviewers. The full manuscripts of potentially eligible studies were retrieved and assessed by both reviewers against the inclusion and exclusion criteria. Disagreements in the application of inclusion or exclusion criteria were resolved by consensus and/or consultation with two other reviewers.

Outcome measures: A wide range of outcomes was considered, to reflect the various dimensions that influence patient choice:

(i) Health technology-related outcomes (including ease of use, portability and convenience);

(ii) Behavioural outcomes (including perceived benefits, perceived barriers, satisfaction and fear/discomfort of needles);

(iii) Adverse reactions (including fear of pain and injection site reactions)

Data extraction: Data were extracted on: (1) description of study; (2) characteristics of the 171 population and intervention; (3) types of outcome measures; (4) any measured revealed 172 preferences (adherence); (5) comparators; (6) study type; (7) results and (8) characteristics 173 of study sponsors and links to authors. 
174 Data analysis: Results were primarily presented narratively [14] with strength of patients'

175 choices assessed from the statistical significance reported or inferred from individual studies.

176 The potential to perform a quantitative (meta)-analysis was specified a priori, conditional on

177 a rigorous assessment of clinical, methodological and statistical heterogeneity between

178 studies. We were cognisant of the dangers of synthesising results from diverse studies as

179 this could lead to biased assessments and give rise to misleading results. We therefore

180 limited any quantitative analysis of the data to studies that: (i) compared a common drug, (ii)

181 made the same comparison among 2 (or more) devices /routes of administration (we

182 excluded studies in which comparators were not described in full), (iii) reported a common outcome, and (iv) used a common method of assessing outcomes (methods that were not validated or not reported were excluded). Meta-analyses of eligible studies were performed in RevMan version 5 (Cochrane Collaboration) using random effects modelling to assess the pooled mean difference (for continuous variables) or odds ratio (for dichotomous variables).

$\underline{\text { Results }}$

Number of studies: A total of 2,337 articles relating to patient preferences for SC medications were identified. Following de-duplication and screening, 85 were judged suitable for inclusion. The PRISMA flow diagram of the search and screening process is presented in Figure 1. A summary of the main characteristics of each paper is presented in Supplementary Online Appendix 1.

Study populations: Sample sizes ranged from 19 to 6,528 people. The majority involved 197 administration of insulin for the management of diabetes ( $n=51$ studies), followed by growth hormone deficiency $(n=10)$, migraine $(n=5)$ and multiple sclerosis $(n=4)$. Other areas included HIV, infertility, contraception, chronic kidney disease, and rheumatoid arthritis. The age range of patients from whom views were obtained directly was 3.5 to 95 years. 
202 Study characteristics: The studies described 102 separate comparisons (Figure 2), with the majority considering alternative means of SC administration (Table 1). No details on the type of SC device were given for 16 comparisons, and there was incomplete information on how multiple daily injections (MDI) were achieved in a further 16 comparisons involving insulin.

206

A variety of study designs were described. Forty-three were randomised studies, 29 were cross-over trials and 18 were parallel arm studies. The duration of clinical studies ranged from 1 week to 2 years. The majority used generic or disease-specific questionnaires; 16 used open-ended questioning or semi-structured interviews. Nine studies used Likert scales, and 12 studies used other rating scales, including a visual analogue scale. Five studies sought to elicit stated preferences for routes of administration using choice-based methods including discrete choice experiment (DCE), adaptive conjoint analysis (ACA) and time trade-off (TTO) analysis. Some studies used simulated injections to obtain information on ease of administration. Table 2 summarises the methods used to elicit preference.

The majority of studies stated links with one or more organisations likely to have commercial interest in the outcomes. The level of involvement ranged from provision of specific costs such as translation or equipment, to direct study funding and/or authorship, receipt of grants or being an advisory board member.

Main study findings: Results from four studies comparing SC administration with intramuscular (IM) injection [16-19] were mixed. While one observational study of interferonbeta-1a in patients with multiple sclerosis found a significant difference in patients' desire to change or discontinue treatment adherence at 1-year in favour of IM with the number of injection site reactions reported as an important factor [16], another suggested a preference towards SC administration [17]. The findings of two studies of the contraceptive 
medroxyprogesterone acetate were similarly inconclusive, with one indicating a tendency towards higher satisfaction with SC [18], and the other showing no statistically significant difference in in reported measures of satisfaction [19].

Inhaled insulin was preferred to SC insulin in all included studies [20-26]. However all studies reported ties with the manufacturers of inhaled insulin technologies. The possibility of publication bias could not be rejected.

Comparisons of SC injection with oral administration did not reveal any statistically significant differences in preference. In two surveys presenting hypothetical scenarios to patients with migraine, there was a tendency for the oral route being preferred, [31] and for formulation type to be more important than speed of onset [27]. However two clinical comparisons of sumatriptan suggested the opposite, with SC formulation tending to be preferred [28,29]. A DCE among patients with osteoporosis indicated that patients would be willing to pay $€ 142$ a month for a daily SC injection rather than a daily or weekly tablet [30].

Four of the comparisons of oral and SC formulations in migraine also considered nasal administration but none demonstrated any statistically significant difference in preference $[27-29,31]$.

Two studies compared SC with transdermal administration [31,32]. In a crossover study of insulin delivery, significantly more patients with type 1 or 2 diabetes stated that they would switch to a patch treatment, if available [32].

Among studies comparing needle-free injector devices (NFID) with SC injections, four compared enfuvirtide delivered via NFID and needle and syringe in patients with HIV. All found significant differences in favour of NFID in terms of patient-rated ease of use [33], 
preference [35], or a desire to continue with the NFID at the end of the study [34, 36]. However, there was no significant difference in patient satisfaction among women selfadministering gonadotropin for infertility treatment [37], or in three studies of children receiving growth hormone therapy [38-40].

Nine comparisons of autoinjector devices with vial and syringe and/or pre-filled syringes (PFS) or other auto-injectors were identified. An adaptive conjoint analysis of users of growth hormone therapy revealed autoinjection to generate higher utility [38]. Autoinjectors for adalimumab were preferred to PFS and associated with less injection site pain in patients with rheumatoid arthritis $[41,42]$. Autoinjectors were similarly preferred for darbopoetin in chronic kidney disease [43] and for sumatriptan in migraine [48]. While one study of autoinjector devices for growth hormone found a preference among both patients and parents [45], another found less favourable scores compared with pen devices, largely due to the requirement for reconstitution [44]. Studies of interferon beta 1a autoinjectors in multiple sclerosis yielded varying results. One found no significant changes from baseline in a disease-specific treatment concern questionnaire [46] while another suggested a preference for autoinjectors [47].

Of 12 papers comparing insulin via SC catheter (mainly continuous SC infusion) with multiple daily injections (MDI) [49-60], 9 found significant differences in favour of administration by infusion, through a range of largely disease-specific measures [49-54,5759].

Eighteen studies compared SC administration using pen devices with syringes, 17 using traditional syringe and vial. These were largely for insulin in diabetes, but also treatments of psoriasis [61], growth hormone deficiency [62], infertility [63,64] and hepatitis C [65]. Pens 
were significantly preferred in 15 studies, particularly with respect to ease of use, convenience and portability [61-64,66-74,76-78].

The largest number of comparisons was between different pen devices, including 22 for administration of insulin [74-75,77-96], and 4 for growth hormone [97-100]. However, 13 insulin and 3 growth hormone studies used simulated injections and no clinical study of pen devices was longer than 12 weeks. All claimed advantages for the novel device over comparators, with statistically significant differences in 19, but all were authored and/or sponsored by manufacturers.

Among all the studies examined, only 12 assessed adherence or persistence as a revealed preference $[16,19,26,35,36,40-42,62,65,71,73]$, and most of these relied on patient selfreport.

Meta analyses: Four groups of studies were considered eligible for meta-analyses, each of which compared insulin delivered using pen devices versus some alternative method (see Supplementary Online Appendix 2). These were: (i) the assessment of patients' satisfaction compared with continuous SC infusion [51,57], (ii) patient preference for a new pen device versus their existing pen device $[80,81,83,92,94]$, (iii) preference compared with SC needle and syringe $[68,71]$, and (iv) preferences in comparison to any existing method of administration [74,78-79].

The comparison of pen devices with SC needle and syringe yielded a pooled odds ratio of 6.7 (95\% confidence interval 4.6, 9.7; heterogeneity $\mathrm{I}^{2}=0 \%$ ) for patients favouring pen devices. However as this represented only 2 of 13 studies making this comparison the potential for selection bias cannot be excluded. All other comparisons we statistically heterogeneous $\left(1^{2} \geq 98 \%\right)$ and therefore deemed unreliable. 


\section{Discussion}

311 An understanding of patients' perspectives on the methods and routes of drug delivery is an important consideration for maximising the effectiveness of medicines. Our systematic review identified wide-ranging evidence using a range of methods of assessing patients' stated and actual choice for SC versus alternative routes of drug administration, as well as between different SC injectable devices. The principal findings were: increased satisfaction and preferences with respect to the ergonomics, convenience and portability of insulin pen devices and autoinjectors as compared to needle \& syringe, and more satisfaction with inhaled insulin; but no clear favouring of oral, SC infusion, intramuscular injection, and needle-free injection devices when compared with SC injections.

A significant number of studies meeting our inclusion criteria were of methods of insulin delivery, reflecting developments in pen devices and the (now discontinued) inhaler, Exubera. Satisfaction with, and preference for different insulin devices and routes of administration may relate more to the necessity for a convenient and pain-free method, given the need for punctual and life-long therapy. By contrast, studies in migraine, where the need for medication is intermittent and unpredictable, having available options of routes of administration for use in different circumstances may be more important to patients than any single preferred option. These contrasts suggest that factors important for patient choice of a given route of administration will vary with the clinical situation and context of use.

The number of studies comparing SC administration with oral, nasal, transdermal and intramuscular administration were each very small, and covered different therapeutic areas. None of the studies compared SC self-administration with intravenous administration by health care professionals in a clinical setting, which we perceive to be increasing with the 
introduction of novel biologic therapies. The comparison with clinic-administration by IM injection of medroxyprogesterone acetate as a contraceptive was perhaps the closest situation, but neither study revealed any difference from a patient's perspective $[18,19]$.

Whilst our review complied with best methodological practice, the strength of our findings is limited by the weaknesses of the research identified and the variety of approaches employed. The number of studies comparing SC injection with non-SC routes was small for each route and many studies were observational, unmasked, had small sample sizes and short follow-up periods. There was general inadequacy in the descriptions of the technologies being assessed, or of the methods of analysis. Although some studies did not disclose a source of funding, the majority were supported by (or linked to) pharmaceutical companies seeking to differentiate their products from those of competitors. As more biopharmaceutical products are developed, and treatments previously administered intravenously are formulated for SC administration, more patient-centred evaluations are likely to emerge, however this should not be at the expense of methodological rigour.

Reviewed studies employed a range of methods, including direct questioning of patients, typically with responses on Likert scales, for their satisfaction with or preference to different treatment options. Such surveys employed a variety of questionnaire designs, only some of which were recognised as validated. The discrete choice experiments or conjoint analyses employed in a small number of studies are a more appropriate choice-based method of preference elicitation grounded in theory [101]. There was considerable heterogeneity among studies, in terms of populations, treatments, methods of drug administration, outcome measure and measurement, to enable unbiased pooled estimates to be determined through meta-analyses in all but one comparison [102]. Combining heterogeneous studies could compromise the systematic and scientifically rigorous representation of empirical evidence that could be more accurately reported in our narrative synthesis [14]. 
360 Our systematic review has extended previous reviews $[10,103]$, which were restricted to

361 comparisons of pen versus needle and syringe insulin for diabetes. Our findings suggest that

362 differences in patients' perspectives between methods and routes of drug delivery will affect

363 choice of delivery device across a whole spectrum of diseases. But while evidence of patient

364 preference - in addition to all features/attributes of medicines (such as efficacy, safety, route

365 of administration) - may potentially add value to treatments, health technology assessments

366 require evidence on how this improves health outcomes and /or cost-effectiveness to justify

367 any increases in pricing. These were outside the scope of the present review, but even so,

368 very few studies considered patient adherence to treatment that might mediate

369 improvements in health outcomes.

370 The implications of our findings are: firstly, that medicines may be optimised by considering

371 patient choice in the clinical decision to prescribe a particular method or route of

372 administration. Prescribers should be alert to the alternative options for subcutaneously

373 administered medicines, and consider the range of factors that are likely to influence

374 patients' adherence with treatment. Secondly, pharmaceutical companies often cite patient

375 preference as a justification for price premiums. Their value dossiers and health technology

376 assessment reports typically suggest that patients favour some methods or routes of drug

377 administration more than others, and that this can lead to improvement in health outcomes.

378 Our review illustrates that evidence underpinning such claims is weak.

380 Conclusions

382 The review identified a number of studies showing the importance of the methods and routes 383 of drug delivery on patient choice. To improve the evidence base, however, we propose that 384 future studies of patients' perspectives of injectable devices should consider using validated 385 preference measures, combined with a choice-based experiment for stated preference 
386 elicitation, and reliable adherence measurement [5] for revealed preferences. Studies need 387 to be unbiased and appropriately powered for demonstrating statistical significance.

388

389 
1. CG76 Medicines adherence: NICE guideline, 28 January 2009, Available from: http://guidance.nice.org.uk/CG76/NICEGuidance/pdf/English Accessed 4th August 2015.

2. NICE Medicines and Prescribing Centre. Medicines Optimisation: The Safe and 
11. Asche CV, Shane-McWhorter L, Raparla S. Health economics and compliance of vials/syringes versus pen devices: a review of the evidence. Diabetes Technol Ther. 2010;12 (suppl 1):S101-8.

12. All Wales Systematic Reviews Register, Cardiff University Systematic Review Network -SysNet. Available from:

http://www.cardiff.ac.uk/insrv/libraries/sure/sysnet/awsrr/patient preferences for subcutaneous medications.pdf Accessed 4th August 2015.

13. Booth A, Clarke M, Ghersi D, Moher D, Petticrew M, Stewart L. An international registry of systematic-review protocols. Lancet. 2010;377:108-9.

14. Systematic Reviews: CRD's guidance for undertaking systematic reviews in health care. Published 2009. ISBN: 1900640473. Available from: http://www.york.ac.uk/inst/crd/SysRev/!SSL!/WebHelp/SysRev3.htm Accessed 4th August 2015.

15. Liberati A, Altman DG, Tetzlaff J, Mulrow C, Gotzsche P, lonnadis JPA, Clarke M, Devereaux PJ. Kleijnen J, Moher D. The PRISMA statement for reporting systematic reviews and meta-analyses of studies that evaluate healthcare interventions: explanation and elaboration. BMJ. 2009;339:b2700.

16. Beer K, Muller M, Hew-Winzeler AM, Bont A, Maire P, You X, Foulds P, Marlind J, Curtius D. The prevalence of injection-site reactions with disease-modifying therapies and their effect on adherence in patients with multiple sclerosis: an observational study. BMC Neurol. 2011;11:144.

17. Lugaresi A, Durastanti V, Gasperini C, Lai M, Pozzilli C, Orefice G, Sotgiu S, Pucci E, Ardito B, Millefiorini E and the CoSa Study Group. Safety and tolerability in relapsingremitting multiple sclerosis patients treated with high-dose subcutaneous interferonbeta by rebiject autoinjection over a 1-year period: The CoSa study. Clin Neuropharmacol. 2008;31:167-72. 
18. Lakha F, Henderson C, Glasier A. The acceptability of self-administration of subcutaneous Depo-Provera. Contraception. 2005;72:14-8.

19. Cameron ST, Glasier A, Johnstone A. Pilot study of home self-administration of subcutaneous depo-medroxyprogesterone acetate for contraception. Contraception. 2012;85:458-64

20. Gerber RA, Cappelleri JC, Kourides IA, Gelfand RA. Treatment satisfaction with inhaled insulin in patients with type 1 diabetes: a randomized controlled trial. Diabetes Care. 2001;24:1556-9.

21. Cappelleri JC, Cefalu WT, Rosenstock J, Kourides IA, Gerber RA. Treatment satisfaction in type 2 diabetes: a comparison between an inhaled insulin regimen and a subcutaneous insulin regimen. Clin Ther. 2002;24:552-64.

22. Hayes RP, Muchmore D, Schmitke J. Effect of inhaled insulin on patient-reported outcomes and treatment preference in patients with type 1 diabetes. Curr Med Res Opin. 2007;23:435-42.

23. Chancellor J, Aballea S, Lawrence A, Sheldon R, Cure S, Plun-Favreau J, Marchant N. Preferences of patients with diabetes mellitus for inhaled versus injectable insulin regimens. Pharmacoeconomics. 2008;26:217-34.

24. Freemantle N, Blonde L, Duhot D, Hompesch M, Eggertsen R, Hobbs FDR, Martinez L, Ross S, Bolinder B, Stridde E. Availability of inhaled insulin promotes greater perceived acceptance of insulin therapy in patients with type 2 diabetes. Diabetes Care. 2005;28:427-8.

25. Rosenstock J, Cappelleri JC, Bolinder B, Gerber RA. Patient satisfaction and glycemic control after 1 year with inhaled insulin (Exubera) in patients with type 1 or type 2 diabetes. Diabetes Care. 2004;27:1318-23.

26. Testa MA, Simonson DC. Satisfaction and quality of life with premeal inhaled versus injected insulin in adolescents and adults with type 1 diabetes. Diabetes Care. 2007;30:1399-405. 
27. MacGregor EA, Brandes J, Eikermann A, Giammarco R. Impact of migraine on patients and their families: the Migraine And Zolmitriptan Evaluation (MAZE) survey-Phase III. Curr Med Res Opin. 2004;20:1143-50.

28. Weidmann E, Unger J, Blair S, Friesen C, Hart C, Cady R. An open-label study to assess changes in efficacy and satisfaction with migraine care when patients have access to multiple sumatriptan succinate formulations. Clin Ther. 2003;25:235-46.

29. Kaniecki RGR. Mixing sumatriptan: a prospective study of stratified care using multiple formulations. Headache. 2001;41:862-6.

30. Darba J, Restovic G, Kaskens L, Balbona MA, Carbonell A, Cavero P, Jordana M, Prieto C, Molina A, Padro I. Patient preferences for osteoporosis in Spain: a discrete choice experiment. Osteoporos Int. 2011;22:1947-54.

31. MacGregor EA, Brandes J, Eikermann A. Migraine prevalence and treatment patterns: the global Migraine and Zolmitriptan Evaluation survey. Headache. 2003;43:19-26.

32. Bohannon N, Bergenstal R, Cuddihy R, Kruger D, List S, Massaro E, Molitch M, Raskin P, Remtema H, Strowig S, Whitehouse F, Brunelle RL, Dreon D, Tan M. Comparison of a novel insulin bolus-patch with pen/syringe injection to deliver mealtime insulin for efficacy, preference, and quality of life in adults with diabetes: A randomized, crossover, multicenter study. Diabetes Technol Ther. 2011;13:1031-7.

33. Harris M, Joy R, Larsen G, Valyi M, Walker E, Frick LW, Palmatier RM, Wring SA, Montaner JSG. Enfuvirtide plasma levels and injection site reactions using a needlefree gas-powered injection system (Biojector). AIDS. 2006;20:719-23.

34. Boyd MA, Truman M, Hales G, Anderson J, Dwyer DE, Carr A. A randomized study to evaluate injection site reactions using three different enfuvirtide delivery mechanisms (the OPTIONS study). Antivir Ther. 2008;13:449-53.

35. Lalezari JP, Saag M, Walworth C, Larson P. An open-label safety study of enfuvirtide injection with a needle-free injection device or needle/syringe: The Biojector 2000 open-label safety study (BOSS). AIDS Res Hum Retroviruses. 2008;24:805-13. 
36. Gottlieb M, Thommes JA, WAND Study Team. Short communication safety, tolerability and pharmacokinetics of enfuvirtide administered by a needle-free injection system compared with subcutaneous injection. Antivir Ther. 2008;13:723-7.

37. Solnica A, Oh C, Cho MM, Loughli JS, McCulloh DH, McGovern PG. Patient satisfaction and clinical outcome after injecting gonadotropins with use of a needle-free carbon dioxide injection system for controlled ovarian hyperstimulation for in vitro fertilization. Fertil Steril. 2009;92:1369-71.

38. Ahmed SFS, Smith WAW, Blamires CC. Facilitating and understanding the family's choice of injection device for growth hormone therapy by using conjoint analysis. Arch Dis Child. 2008;93:110-4.

39. Dorr HG, Zabransky S, Keller E, Otten BJ, Partsch C-J, Nyman L, Gillespie BK, Lester NR, Wilson AM, Hyren C, van Kuijck MA, Schuld P, Schoenfeld SL. Are needle-free injections a useful alternative for growth hormone therapy in children? Safety and pharmacokinetics of growth hormone delivered by a new needle-free injection device compared to a fine gauge needle. J Pediatr Endocrinol Metab. 2003;16:383-92.

40. Wickramasuriya BPNB, Casey AA, Akhtar SS, Zia R, Ehtisham S, Barrett TG, Shaw NJ, Kirk JMW. Factors determining patient choice of device for GH therapy. Horm Res. 2006;65:18-22.

41. Borrs-Blasco J, Gracia-Prez A, Rosique-Robles JD, Castera MD-E, Abad FJ. Acceptability of switching adalimumab from a prefilled syringe to an autoinjection pen. Expert Opin Biol Ther. 2010;10:301-7.

42. Kivitz A, Cohen S, Dowd JE, Edwards JE, Thakker S, Wellborne FR, RRenz CL, Segurado OG. Clinical assessment of pain, tolerability, and preference of an autoinjection pen versus a prefilled syringe for patient self-administration of the fully human, monoclonal antibody adalimumab: the TOUCH trial. Clin Ther. 2006;28:161929. 
43. Lim WH, Chan D, Boudville N, Pellicano S, Herson $\mathrm{H}$, Moody $\mathrm{H}$, Hutchison B, Snedeker M, Dogra G. Patients' Perceptions of Subcutaneous Delivery of Darbepoetin Alfa by Autoinjector Prefilled Pen Versus Prefilled Syringe: A Randomized, Crossover Study. Clin Ther. 2012;34:1948-53.

44. Pfutzner A, Hartmann K, Winter F, Fuchs GS, Kappelgaard A-M, Rohrer TR. Intuitiveness, ease of use, and preference of a prefilled growth hormone injection pen: a noninterventional, randomized, open-label, crossover, comparative usability study of three delivery devices in growth hormone-treated pediatric patients. Clin Ther. 2010;32:1918-34

45. Stanhope R, Buchanan C, Butler G, Costigan C, Dunger D, Greene S, Hoey H, Hughes I, Kelnar C, Kirk, J, Komulainen J, Lowry M, Warner M. An open-label acceptability study of Norditropin SimpleXx - A new liquid growth hormone formulation. J Pediatr Endocrinol Metab. 2001;14:735-40.

46. Devonshire V, Arbizu T, Borre B, Lang M, Lugaresi A, Singer B, Verdun di Cantogno E, Cornelisse P. Patient-rated suitability of a novel electronic device for self-injection of subcutaneous interferon beta-1a in relapsing multiple sclerosis: An international, single-arm, multicentre, Phase IIlb study. BMC Neurol. 2010;10:28.

47. Wray S, Armstrong R, Herrman C, Calkwook J, Cascione M, Watsky E, Hayward B, Mercer B, Dangond F. Results from the single-use autoinjector for self-administration of subcutaneous interferon beta-1a in patients with relapsing multiple sclerosis (MOSAIC) study. Expert Opin Drug Deliv. 2011;8:1543-53.

48. Landy S, H., Tepper S, J., Wein T, Schweizer E, Ramos E. An Open-Label Trial of a Sumatriptan Auto-Injector for Migraine in Patients Currently Treated With Subcutaneous Sumatriptan An Open-Label Trial of a Sumatriptan Auto-Injector for Migraine in Patients Currently Treated With Subcutaneous Sumatriptan. Headache. 2013;53:118-25. 
49. Rubin RR, Peyrot M. Health-Related Quality of Life and Treatment Satisfaction in the Sensor-Augmented Pump Therapy for A1C Reduction 3 (STAR 3) Trial. Diabetes Technol Ther. 2012;14:143-51.

50. Marmolin ES, Brodsgaard J, Gjessing HJ, Schousboe K, Grodum E, Jorgensen UL, Moller CC, Pedersen J. Better treatment of outpatients with type 1 diabetes after introduction of continuous subcutaneous insulin infusion. Dan Med J. 2012;59:A4445.

51. Skogsberg L, Fors H, Hanas R, Chaplin JE Lindman E, Skogsberg J. Improved treatment satisfaction but no difference in metabolic control when using continuous subcutaneous insulin infusion vs. multiple daily injections in children at onset of type 1 diabetes mellitus. Pediatr Diabetes. 2008;9:472-9.

52. Garmo A, Pettersson-Frank B, Ehrenberg A. Treatment effects and satisfaction in diabetic patients changing from multiple daily insulin injections to CSII. Practical Diabetes Int. 2004;21:7-12.

53. Nicolucci A, Maione A, Franciosi M, Amoretti R, Busetto E, Capani F, Bruttomesso D, Di Bartolo P, Girelli A, Leonetti F, Morviducci L, Ponzi P, Vitacolonna E. Quality of life and treatment satisfaction in adults with Type 1 diabetes: a comparison between continuous subcutaneous insulin infusion and multiple daily injections. Diabet Med. 2008;25:213-20.

54. Hanas R, Adolfsson P, Elfvin-Akesson K, Hammaren L, Ilvered R, Jansson I, Johansson C, Kroon M, Lindgren J, Lindh A, Ludvigsson J, Sigstrom L, Wilk A, Aman J. Indwelling catheters used from the onset of diabetes decrease injection pain and pre-injection anxiety. J Pediatr. 2002;140:315-20.

55. Herman WH, Ilag LL, Johnson SL, Martin CL, Sinding J, HArthi A, Plunkett CD, LaPorte FB, Burke R, Brown MB, Halter JB, Raskin P. A clinical trial of continuous subcutaneous insulin infusion versus multiple daily injections in older adults with type 2 diabetes. Diabetes Care. 2005;28:1568-73. 
56. Nuboer R, Borsboom GJ, Zoethout JA, Koot HM, Bruining J. Effects of insulin pump vs. injection treatment on quality of life and impact of disease in children with type 1 diabetes mellitus in a randomized, prospective comparison. Pediatr Diabetes. 2008;9:291-6.

57. Raskin P, Bode BW, Marks JB, Hirsch IB, Weinstein RL, McGill JB, Peterson GE, Mudaliar SR, Reinhardt RR. Continuous subcutaneous insulin infusion and multiple daily injection therapy are equally effective in type 2 diabetes: a randomized, parallelgroup, 24-week study. Diabetes Care. 2003;26:2598-603.

58. Scheidegger U, Allemann S, Scheidegger K, Diem P. Continuous subcutaneous insulin infusion therapy: effects on quality of life. Swiss Med Wkly. 2007;137:476-82.

59. Weintrob N, Benzaquen H, Galatzer A, Shalitin S, Lazar L, Fayman G, Lilos P, Dickerman Z, Phillip M. Comparison of continuous subcutaneous insulin infusion and multiple daily injection regimens in children with type 1 diabetes: a randomized open crossover trial. Pediatrics. 2003;112:559-64.

60. Wilson DM, Buckingham BA, Kunselman EL, Sullivan MM, Paguntalan HU, Gitelman SE. A two-center randomized controlled feasibility trial of insulin pump therapy in young children with diabetes. Diabetes Care. 2005;28:15-9.

61. Paul C, Stalder JF, Thaci D, Vincendon P, Brault Y, Kielar D, Tebbs V. Patient satisfaction with injection devices: A randomized controlled study comparing two different etanercept delivery systems in moderate to severe psoriasis. J Eur Acad Dermatology Venereol. 2012;26:448-55.

62. Drent ML, Jakobsdottir S, Van Wijk JAE, Oostdijk W, Wit JM. Acceptability of liquid human growth hormone (hGH) [Norditropin SimpleXx] in adults and children with $\mathrm{GH}$ deficiency and children with chronic renal disease. Clin Drug Invest. 2002;22:633-8.

63. Bruynesteyn KK, Bonsel GJG, Braat DDMD, Fauser BCJM, Devroey P, van Genugten MLL. Economic evaluation of the administration of follitropin-beta with a pen device. Reprod Biomed Online. 2005;11:26-35. 
64. Platteau P, Laurent E, Albano C, Osmanagaolu K, Vernaeve V, Tournaye H, Camus M, Van Steirteghem A, Devroey P. An open, randomized single-centre study to compare the efficacy and convenience of follitropin beta administered by a pen device with follitropin alpha administered by a conventional syringe in women undergoing ovarian stimulation for IVF/ICSI. Hum Reprod. 2003;18:1200-4.

65. Cadranel JF, Boujenah JL, Bourliere M, Fontanges T, Pol S, Trepo C, Ouzan. Satisfaction of patients treated for chronic hepatitis $C$ with the peginterferon alfa-2b pen device: the VISA observational study. Gastroenterol Clin Biol. 2007;31:180-4.

66. Pfutzner A, Bailey T, Campos C, Kahn D, Ambers E, Niemeyer M, Guerrero G, Klonoff D, Nayberg I. Accuracy and preference assessment of prefilled insulin pen versus vial and syringe with diabetes patients, caregivers, and healthcare professionals. Curr Med Res Opin. 2013;29:475-81.

67. Bode B, Shelmet J, Gooch B, Hassman DR, Liang J, Smedegaard JK, Sklovlund S, Berg B, Lyness W, Schneider SH and InDuo Study Group. Patient perception and use of an insulin injector/glucose monitor combined device. Diabetes Educ. 2004;30:301-9.

68. Korytkowski M, Bell D, Jacobsen C, Suwannasari R. A multicenter, randomized, openlabel, comparative, two-period crossover trial of preference, efficacy, and safety profiles of a prefilled, disposable pen and conventional vial/syringe for insulin injection in patients with type 1 or 2 diabetes mellitus. Clin Ther. 2003;25:2836-48.

69. Lee IT, Liu HC, Liau YJ, Lee W-J, Huang C-N, Sheu WHJ-H. Improvement in healthrelated quality of life, independent of fasting glucose concentration, via insulin pen device in diabetic patients. J Eval Clin Pract. 2009;15:699-703.

70. Shelmet J, Schwartz S, Cappleman J, Peterson G, Skovlund S, Lytzen L, Nicklasson L, Liang J, Lyness W. Preference and resource utilization in elderly patients: InnoLet versus vial/syringe. Diabetes Res Clin Pract. 2004;63:27-35. 
71. Stockl K, Ory C, Vanderplas A, Nicklasson L, Lyness W, Cobden D, Change E. An evaluation of patient preference for an alternative insulin delivery system compared to standard vial and syringe. Curr Med Res Opin. 2007;23:133-46.

72. Summers KH, Szeinbach SL, Lenox SM. Preference for insulin delivery systems among current insulin users and nonusers. Clin Ther. 2004;26:1498-505.

73. Wilk T, Mora PF, Chaney S, Shaw K. Use of an insulin pen by homeless patients with diabetes mellitus. J Am Acad Nurse Pract. 2002;14:372-9.

74. Rubin RR, Peyrot M. Quality of life, treatment satisfaction, and treatment preference associated with use of a pen device delivering a premixed 70/30 insulin aspart suspension (aspart protamine suspension/soluble aspart) versus alternative treatment strategies. Diabetes Care. 2004;27:2495-7.

75. Stocks A, Perry S-R, Brydon P. HumaPen Ergo: A new 3.0ml Reusable insulin pen evaluation of patient acceptability. Clin Drug Invest. 2001;21:319-24.

76. Fox C, McKinnon C, Wall A, Lawton SA. Ability to handle, and patient preference for, insulin delivery devices in visually impaired patients with type 2 diabetes. Pract Diabetes Int. 2002;19:104-7.

77. Ignaut DA, Schwartz SL, Sarwat S, Murphy HL. Comparative device assessments: Humalog KwikPen compared with vial and syringe and FlexPen. Diabetes Educ. 2009;35:789-98

78. Israel-Bultman H, Hyllested-Winge J, Kolaczynski M, Steindorf J, Garon J. Comparison of preference for NovoPen((R)) 4 with previous insulin pen treatments after 12 weeks in adult patients with type 1 and type 2 diabetes: a multicenter observational study. Clin Ther. 2011;33:346-57.

79. Venekamp WJ, Kerr L, Dowsett SA, Johnson PA, Wimberley D, McKenzie C, Malone J, Milicevic Z. Functionality and acceptability of a new electronic insulin injection pen with a memory feature. Curr Med Res Opin. 2006;22:315-25. 
80. Bailey T, Thurman J, Niemeyer M, SchmeisI G. Usability and preference evaluation of a prefilled insulin pen with a novel injection mechanism by people with diabetes and healthcare professionals. Curr Med Res Opin. 2011;27:2043-52.

81. Guo X, Sommavilla B, Vanterpool G, Qvist M, Bethien M, Lilleore SK. Evaluation of a new durable insulin pen with memory function among people with diabetes and healthcare professionals. Expert Opin Drug Deliv. 2012;9:355-6.

82. Hancu N, Czupryniak L, Genestin E, Sourij H. A Pan-European and Canadian prospective survey to evaluate patient satisfaction with the SoloSTAR insulin injection device in type 1 and type 2 diabetes. J Diabetes Sci Technol. 2011;5:1224-34.

83. Nadeau DA, Campos C, Niemeyer M, Bailey T. Healthcare professional and patient assessment of a new prefilled insulin pen versus two widely available prefilled insulin pens for ease of use, teaching and learning. Curr Med Res Opin. 2012;28:3-13.

84. Niskanen L, Jensen LE, Rastam J, Nygaard-Pedersen L, Erichsen K, Vora JP. Randomized, multinational, open-label, 2-period, crossover comparison of biphasic insulin aspart 30 and biphasic insulin lispro 25 and pen devices in adult patients with type 2 diabetes mellitus. Clin Ther. 2004;26:531-40.

85. Reimer T, Hohberg C, Pfutzner A, Jorgensen C, Jensen KH, Pfutzner A. Intuitiveness, instruction time, and patient acceptance of a prefilled insulin delivery device and a reusable insulin delivery device in a randomized, open-label, crossover handling study in patients with type 2 diabetes. Clin Ther. 2008;30:2252-62.

86. Ristic S, Bates PC, Martin JM, Llewelyn JA. Acceptability of a reusable insulin pen, Humapen Ergo, by patients with type 1 and type 2 diabetes. Curr Med Res Opin. 2002;18:68-71.

87. Schipper C, Musholt P, Niemeyer M, Loffler A, Forst T, Pfutzner A. Patient device assessment evaluation of two insulin injection devices in a mixed cohort of insulintreated patients with type 1 or type 2 diabetes mellitus. Curr Med Res Opin. 2012;28:1297-303. 
88. Asakura $\mathrm{T}$, Seino $\mathrm{H}$, Jensen $\mathrm{KH}$. Patient acceptance and issues of education of two durable insulin pen devices. Diabetes Technol Ther. 2008;10:299-304.

89. Gottesman I, Perron P, Berard L, Stewart J, Basso N, Mettimano K, Elliott T. Evaluation of a new reusable insulin pen (ClikSTAR) in Canadian patients with type 1 and type 2 diabetes mellitus receiving insulin glargine. Diabetes Technol Ther. 2012;14:926-35.

90. Asakura T, Jensen $\mathrm{KH}$. Comparison of intuitiveness, ease of use, and preference in two insulin pens. J Diab Sci Technol. 2009;3:312-9.

91. Garg S, Bailey T, DeLuzio T, Pollom D. Preference for a new prefilled insulin pen compared with the original pen. Curr Med Res Opin. 2011;27:2323-33.

92. Haak T, Edelman S, Walter C, Lecointre B, Spollett G. Comparison of usability and patient preference for the new disposable insulin device SoloStar versus FlexPen, Lilly disposable pen, and a prototype pen: an open-label study. Clin Ther. 2007;29:650-60.

93. Olsen BS, Lilleore SK, Korsholm CN, Kracht T. Novopen Echo for the delivery of insulin: a comparison of usability, functionality and preference among pediatric subjects, their parents, and health care professionals. J Diabetes Sci Technol. 2010;4:1468-75.

94. Oyer D, Narendran P, Qvist M, Niemeyer M, Nadeau DA. Ease of use and preference of a new versus widely available prefilled insulin pen assessed by people with diabetes, physicians and nurses. Expert Opin Drug Deliv. 2011;8:1259-69.

95. Sommavilla BB, Jorgensen CC, Jensen KK. Safety, simplicity and convenience of a modified prefilled insulin pen. Expert Opin Pharmacother. 2008;9:2223-32.

96. Sommavilla B, Pietranera G. A randomized, open-label, comparative crossover handling trial between two durable pens in patients with type 1 or 2 diabetes mellitus. Journal Diabetes Sci Technol. 2011;5:1212-21. 
97. Kappelgaard AM, Mikkelsen S, Bagger C, Fuchs GS. Children and adolescent acceptability of a new device system to administer human growth hormone--a pilot study. J Pediatr Endocrinol Metab. 2012;25:285-94.

98. Fuchs GS, Mikkelsen S, Knudsen TK, Kappelgaard A. Ease of use and acceptability of a new pen device for the administration of growth hormone therapy in pediatric patients: an open-label, uncontrolled usability test. Clin Ther. 2009;31:2906-14.

99. Hey-Hadavi J, Pleil A, Deeb LC, Fuqua JS, Silverman LA, Reiner B, Newfield R, Rajicic N, Wajnrajch MP, Cara JF. Ease of use and preference for a new disposable self-injection pen compared with a reusable pen for administering recombinant human growth hormone: A multicenter, 2-Month, single-arm, open-label clinical trial in patientcaregiver dyads. Clin Ther. 2010;32:2036-47.

100. Kappelgaard AM, Mikkelsen S, Knudsen TK, Fuchs GS. Patient preference for a new growth hormone injection device: results of an open-label study in Japanese pediatric patients. J Pediatr Endocrinol Metab. 2011;24:489-96.

101. Ryan M, Gerard K, Amaya-Amya M. Using Discrete Choice Experiments to Value Health and Health Care. The Economics of Non-Market Goods and Resources, Volume 11, Series ed Bateman IJ, Dordrecht: Springer, 2008.

102. Sterne JAC, Egger M, Moher D. Chapter 10: Addressing reporting biases. In: Higgins JPT Green S editor(s). Cochrane Handbook for Systematic Reviews of Interventions. Chichester, UK: John Wiley \& Sons, 2008.

103. Anderson BJ, Redondo MJ. What can we learn from patient-reported outcomes of insulin pen devices? J Diabetes Sci Technol. 2011;5:1563-71. 